Article

\title{
Curriculum Integration in Distance Learning at Primary and Secondary Educational Levels on the Example of eTwinning Projects
}

\author{
Elżbieta Gajek \\ Institute of Applied Linguistics, University of Warsaw, 00-312 Warsaw, Poland; e.gajek@uw.edu.pl \\ Received: 19 November 2017; Accepted: 25 December 2017; Published: 27 December 2017
}

\begin{abstract}
Curriculum integration is one of the concepts which has been discussed for years. Telecollaborative projects, which employ elements of distance learning, provide opportunities for putting the idea into practice. Analysis of eTwinning projects undertaken in Polish schools aims at demonstrating the integrative role of distance learning approaches and their contribution to integration of various themes in educational context. As the eTwinning framework is very flexible, allowing for teacher and students autonomy the projects may vary in the topics, age and number of participants, duration scope within curriculum etc. The study shows various levels and perspectives of curriculum integration which take place in eTwinning projects. It also discusses the role of distance learning at primary and secondary educational levels. The challenge is to transform international collaboration of selected schools an everyday practice for all learners and teachers.
\end{abstract}

Keywords: curriculum integration; language learning; eTwinning; telecollaboration; distance learning

\section{Introduction}

The concept of "'integration' incorporates the idea of unity between forms of knowledge and the respective disciplines" [1] (p. 135). This implies application of methodology and language from various disciplines to deal with a topic or problem [2]. Results of studies show that an integrated curriculum increases intellectual curiosity, improves attitude towards schooling, enhances problem-solving skills and higher achievement in college [3,4]. Barab and Landa indicated that when students focus on problems worth solving, motivation and learning increase [5].

As language is negotiated and constructed between people within social contexts a community is created. Such community of practice has been built within a European eTwinning programme which was launched in 2005. It is a programme aimed at schools. It provides virtual space and organizational support to help teachers find partners in European countries to work together and share mutual interests and develop mutual understanding between young people. An eTwinning project is created by at least two partners-schools from different European countries. Other teachers and schools may join the project, the number of partners is not limited. Sociocultural perspective ascribes an additional advantage to the technology which can extend the community beyond the physical classroom [6]. Through a regular use of digital tools by interacting people who share similar interests a community of practice is created [7] (p. 98). Thus, curriculum integration requires purposeful interactions over linguistic, cultural and disciplinary differences. Such interactions and share of work between participants establish either cooperation or collaboration patterns. "In cooperation, partners split the work, solve sub-tasks individually and then assemble the partial results into the final output. In collaboration, partners do the work 'together'. However, some spontaneous division may occur even when two people do really work together" [8] (p. 8).

In the effective use of technology in subject teaching a special type of teachers' competence has to be developed, that is teacher technological-pedagogical-content competence, which include a common 
area of the three elements [9]. The curriculum integration in a broad community of practice may enhance its development. Teachers are still at different stages of technology adoption, their attitudes to technology interrelates with their pedagogical use of it [10]. Thus, participation in the community of practice by influencing their attitudes contribute to their professional development.

The role of technology in curriculum integration shifts from delivery systems to mediation channels. Technologies serve as slaves to students not masters [11]. Meskill and Ranglova perceive learning with tools as "teacher-orchestrated and student-centred with technology tools stimulating and supporting off-line thinking, discourse and learning" [12] (p. 23). Thus, the role of technology is a tool, resource and catalyst for socially constructed knowledge and understanding [13-15]. Thus, technologies enable to introduce into curriculum integration meaningful learning activities.

Construction of knowledge in international communities of practice refers to Vygotskian social constructivism [16]. According to Crook, cross-cultural collaboration "makes sense of 'learning' by reference to the social structure of activity" [17]. Chapelle also perceives the Vygotskyan concepts as grounds for collaborative net-based language teaching and learning [18].

Intercultural competence as defined by Byram involves a combination of knowledge, skills and attitudes [19]. These factors contribute to curriculum integration through telecollaboration. In this way students and teachers develop intercultural pragmatics [20]. The implementation of telecollaboration projects for curriculum integration is especially important in Poland, a country, where the citizens are not interested in implementation of science and technological achievements in their lives [21,22]. This importance is reflected in the Ministry of Education policy document [23].

There are some studies which demonstrate the impact of eTwinning on learners, teachers and schools [24-27]. As far as curriculum integration is referred the Authors of the final report state that "It appears that curricular integration of project activities is the norm, even when project work per se is not integrated into lesson time. Typically, eTwinning projects might combine elements of language learning and literacy, ICT (as a curriculum subject or skill set), sciences and mathematics and various social science subjects" [24] (p. 8). Another study investigates the impact of eTwinning projects on teachers' practice and training in Romania. Although the teachers' respondents confirm that eTwinning activities enrich the Romanian curriculum by adding interesting and motivating activities. However, they find it difficult to integrate the activities in the curriculum. Half of them identify "a big discrepancy between what the Romanian curriculum allows (contents, expected results, standards and evaluation methods) and what eTwinning proposes" [25] (p. 25). In the comparative study, Nawrot shows that in England half of the teachers claim that the curriculum does not fit in eTwinning activities and there is a big discrepancy between what the English curriculum allows and what eTwinning proposes. On the contrary, $83 \%$ of the teachers' respondents in Poland disagree with the statement that the curriculum does not fit in eTwinning activities but similarly to their Romanian and English colleagues, half of them partially agree with the statement there is a big discrepancy between what the English curriculum allows and what eTwinning proposes. However, the other half partially disagree (33\%) or strongly disagree (17\%) [26]. In a study conducted in Poland majority of 620 language teachers-participants of eTwinning programme confirm that they are able to integrate technology into the curriculum to the extent needed to participate in international projects [27]. Thus, further studies both theoretical and ethnographic are needed to explain the issue of curriculum integration of eTwinning practices in various educational systems. The text demonstrates the premises of an eTwinning project and the analysis of curriculum integration factors in the projects implemented on the basis of Polish schools participating in the programme. It is worth noticing, that the policy introduced to Polish educational system in September 2017 specifies the participation in international projects as one of the conditions for achievement the curricular aims at primary and secondary school levels [23]. Thus, curricular integration, which is one of the premises of the eTwinning programme, has been part of the educational policy. 


\section{Materials and Methods-eTwinning Programme Framework}

Firstly, it is worth noticing the size of the programme. The statistics showing the number of active schools, teachers and projects are presented in Table 1 below (taken on 7 September 2017).

Table 1. Statistical data-teachers, projects and schools participating in eTwinning (Source http:/ / www. etwinning.pl/statystyki-2/).

\begin{tabular}{|c|c|c|c|}
\hline Country & Teachers & Projects & Schools \\
\hline Albania & 1055 & 918 & 2477 \\
\hline Armenia & 694 & 210 & 929 \\
\hline Austria & 1489 & 1465 & 3378 \\
\hline Azerbaijan & 403 & 120 & 341 \\
\hline Belgium & 2496 & 1983 & 5200 \\
\hline Bosnia and Herzegovina & 359 & 406 & 843 \\
\hline Bulgaria & 4359 & 2760 & 6965 \\
\hline Croatia & 2731 & 1455 & 6878 \\
\hline Cyprus & 1373 & 555 & 2075 \\
\hline Czech Republic & 6359 & 3559 & 8920 \\
\hline Denmark & 1756 & 1828 & 6355 \\
\hline Estonia & 2172 & 814 & 3691 \\
\hline Finland & 2613 & 2113 & 5579 \\
\hline France & 16,168 & 18,057 & 41,375 \\
\hline Georgia & 1398 & 303 & 592 \\
\hline Germany & 7997 & 7754 & 18,068 \\
\hline Great Britain & 9417 & 13,176 & 24,368 \\
\hline Greece & 10,553 & 11,127 & 21,132 \\
\hline Hungary & 1804 & 1765 & 3876 \\
\hline Iceland & 749 & 300 & 1211 \\
\hline Ireland & 1092 & 1288 & 1907 \\
\hline Italy & 17,423 & 13,712 & 53,270 \\
\hline Latvia & 2484 & 1094 & 5402 \\
\hline Liechtenstein & 4 & 11 & 16 \\
\hline Lithuania & 4338 & 1784 & 5564 \\
\hline Luxembourg & 225 & 127 & 457 \\
\hline Malta & 1228 & 228 & 2248 \\
\hline Moldova & 572 & 139 & 278 \\
\hline Netherlands & 2284 & 1919 & 6249 \\
\hline Norway & 1939 & 1512 & 4361 \\
\hline Poland & 21,178 & 140,253 & 44,319 \\
\hline Portugal & 5819 & 1593 & 11,440 \\
\hline Republic of Macedonia & 732 & 305 & 661 \\
\hline Romania & 11,900 & 7840 & 22,121 \\
\hline Serbia & 1096 & 844 & 1929 \\
\hline Slovakia & 6422 & 2629 & 7755 \\
\hline Slovenia & 2266 & 664 & 2717 \\
\hline Spain & 15,316 & 13,247 & 40,227 \\
\hline Sweden & 2606 & 3145 & 8503 \\
\hline Tunisia & 574 & 149 & 510 \\
\hline Turkey & 16,749 & 44,065 & 98,313 \\
\hline Ukraine & 1937 & 576 & 1073 \\
\hline Total & 85,564 & 264,733 & 251,535 \\
\hline
\end{tabular}

Since 2005 the eTwinning programme has involved 517,584 teachers, 189,338 schools and 66,313 projects registered [28].

\subsection{Aims of the Study}

The research aims at analysing what is integrating in an eTwinning project and how this integration is implemented from various perspectives. The specific research questions include to 
the stages of project implementation, the content, the teachers' roles, the learners' roles, the models of work, the technology used, the results of the project, the role of the project in the school life, in the local community in the global trends.

\subsection{Projects Analysed}

The number of projects analysed cover over 1800 projects submitted by the participants for the eTwinning National Quality Label. The participants of such projects value their work and through the process of filling in the application form they reflected on the content, cooperation, curriculum integration, pedagogical value of technology, sustainability and transferability and internal evaluation.

\section{Results}

\subsection{Analysis of the Process}

At the introductory stage the majority of projects start with shorter or longer self-description including the lifestyle, customs- that is, the world around as social contacts create the grounds for any collaboration. Some short-term projects end at this stage. Others, particularly aimed at young learners, develop at this stage in detail, in order to provide children with basic linguistic competence covering this area of life, culture and language. In secondary education projects teenagers examine the subcultures of young generations in both countries in detail at this stage.

The next stage is the intercultural level as the well-established acquaintance with partners opens a space for further cooperation. Partners often decide to work on customs, holidays and traditions. They exchange information on what people do and how they celebrate and spend their free time. This helps to elicit children's interest in their own and other cultures. However, sometimes even the events' participants have forgotten why they participate in them. Writing about the customs and traditions is an occasion for them to reflect on the values that are involved in the national or local traditions. These topics are also the usual content of language textbooks, which integrates cultural awareness and intercultural knowledge with teaching a foreign language. While presenting their own culture learners look at it through the eyes of their partners, which is a valuable experience for young generation.

Then, long-term projects start the thematic work negotiated between the teachers with the intensive participation of learners. The themes of such projects are discussed later in this text.

At the last stage evaluation and self-reflection on the content, learning and benefits take place, usually in the forms of surveys or focus group interviews.

\subsection{Analysis of the Content}

The content of projects approved for Quality Label has fallen into 7 overlapping main categories, that is:

- Everyday culture, school educational culture - the most popular theme, present in each project;

- History and traditions, local region culture-widely explored;

- Environmental issues-related to recycling, pollution and protection;

- Knowledge of specific subjects such as maths, science, business;

- Visual arts and music;

- Multilingual and multicultural cooperation;

- Themes neglected in the curriculum.

The other categories are present but less popular:

- Technology — either safety in the internet or exploring digital technology;

- Intercultural issues-beyond simple facts and comparisons, more orientated on intercultural reflection; challenging stereotypes, xenophobia and intolerance;

- Media-role of mass media and digital media in societies. 
A group of projects relates to the past, that is, history and traditions either local or national. Learning about our past in a non-native language and making effort to present own heritage in a way that is attractive to others has an added educational value, which is brought naturally within projects that present architecture, monuments and festivals. Knowledge and ability to present own past equip learners with practical skills for life, as it is a popular topic of conversation with foreigners. Projects relating to the past the may fit into cross-curricular school projects. What is more, learning about the partners' historical values and traditions helps to deeper understand ours. Interest in the traditions of others and respect for them as well as the sensitivity to similarities and differences are the next added values in such projects.

The next category of topics is related to environmental issues, characteristic features of nature in the region and protection of natural heritage. Working on such projects raises awareness of responsibility for the environment. Learners come to realise the global and local aspects of environment protection. Furthermore, in the projects children learn how to identify and present features of their environment attractively. It seems that if schools are located in comparable places, the projects are more successful. A river, seashore, or mountains in the neighbourhood of both partner schools establish a solid ground for cooperation. The importance of environment protection is better understood when both partners suffer city smog or fight against a motorway planned through a natural reserve nearby. A solitary hill with ruins of a castle in the outskirts of both small cities may be a fertile theme of a twin project.

The following category of projects embraces of the most colourful and entertaining activities of all because linguistic and technological tools are harnessed to develop learners artistically. Learners prepare art exhibitions, theatre performances and dance shows in cooperation with partners which is both fun and learning. They also work on literature, myths and fables, e.g., by writing a play together. They get to understand various intercultural aspects of entertainment, having fun in multinational real and virtual environment. However, not many projects undertake topics in the areas of history of visual art or musical traditions.

The category of subject-related projects is relatively small if culture-bound subjects such as Maths, Business, Science, Environment, History, Geography and Nature are placed in separate categories. Maths can be easily taught in a non-native language as it uses its own code. At the same time learners acquire this specific code-mathematical thinking —and the language of description of objects and concepts in mathematics. The cognitive added value of such learning experience should not be neglected. Learning science in a non-native language can be a good training for further academic education and for work in international teams. While working on ICT in foreign languages students may observe various patterns of linguistic borrowings of computer terminology from English to other languages. In projects related to subjects both learners and teachers may collaborate and share experience. Teachers may share methods and approaches to teaching math and science and enterprise.

There are also some very interesting projects that overlap with the categories presented above to some extent only. In these projects learners gain knowledge and develop skills that are neglected in the curriculum. Thus, they extend curriculum by investigating areas which contribute to innovative approach to education. In this group, each project is different. In one, building knowledge on simple information requires interpretative skills; in another, touchy social issues are dealt with.

\subsection{Analysis of Models of Work}

In the projects both collaboration and cooperation are implemented. Partners either work together to obtain a result within a collaborative pattern or each partner does a part of the work individually and they exchange the parts within a cooperative pattern.

On the one hand, in most of the projects learners actually share the same experience, activities and emotions but the content related to their culture is different. Thus, the framework is the same but work is shared cooperatively. 
On the other hand, in collaborative work the authorship of the results as equally shared. This leads to experience of unity in diversity, students learn how to identify and accept similarities and tolerate and respect differences. They enrich their understanding of inclusion in various senses of the concept.

\subsection{Analysis of Mediation}

In a community of practice students notice the role of mediation both-linguistic and culturalin spoken and written texts. Learners translate words, expressions or longer written texts from their native language into a foreign language, mainly English, to share texts with partners. They also translate from a foreign language into Polish to present the results of the project e.g., to friends or parents, or on a blog.

While talking through digital communicators students translate speech. They explain to each other the content, which may not be clear. That may be the case for different reasons, e.g., lack of concentration, differences-individual or group - in the stages of linguistic development, emotions caused by a new means of communication, mistakes made by the interlocutor, who is often a learner of the foreign language. The probability of communication e.g., in English between non-native speakers is much higher than the probability of having a conversation with a native speaker. Thus, it is very important to be aware of the influence of the native language on communication. Students and teachers practice mediation competence in both foreign and native languages, in different text genres. On the one hand, they communicate with partners more or less formally. On the other hand, informally, they present their project to other teachers, family members and friends. Sometimes they participate in formal meetings in their own school or in other schools, or with local or school authorities. They also write official accounts or reports. These tasks influence the way the use both languages for different purposes; that is their pragmatic competence grows.

Cultural mediation competence in and extended community of practice seems to be equally important. For example, in different cultures direct utterances are either accepted or not accepted. The same expression-even grammatically correct in English-in one culture may sound friendly, in another offensive. All experiences gained in different kinds of the mediation activities are developed in a safe eTwinning project, where a student is provided with the teacher's help, explanations and support. They are essential for breaking intercultural barriers and for better communication. These skills are useful in other communities of practice.

\subsection{Analysis of the Teachers' Roles and Input}

The role of the teachers in integration telecollaborative work in the curriculum is pivotal. There are different levels of curricular integration in terms of students' access to international community of practice. Projects in which only one class is involved are usually based on the initiative undertaken by one single teacher. Projects in which the whole school is involved are supported by the head of the school. All of the teachers' participants in the projects are motivated to change their methods of work and to add extra value to their everyday teaching. The teachers' initiative as well as their managerial skills in creation international community of practice are observed. They have decided to open their classes to other learners and teachers. They also prefer learning-by-doing to learning-by-reading. The extended community of practice changes education by removal of the nineteenth-century educational limits, that is, four walls of a classroom, two covers of a textbook and five working days a week can be easily broken with no harm to the educational system as a whole. They remove routine artificial classroom activities from their teaching practice and replace them with socially and affectively meaningful communication tasks which introduce learners to a multilingual and multicultural world.

Most of the projects are targeted directly at learners, which is obvious in education, assuming that teachers get from the collaborative work some additional professional benefits such as satisfaction, experience, confidence, which seem less important. Most of the teachers see themselves as organizers, guides and motivators and in some cases even controllers. Thus, it is worth pointing out that in some projects, aims focused on the teachers are also emphasized. Teachers also want to benefit 
professionally from the participation in the community of practice by exchanging examples of good practice, developing methodology of teaching and sharing with partners methodological advice they get from their teacher trainers. This reflects their creative and exploratory approach to a new teaching environment and new methods of teaching. Thus, integration enhances creativity in teachers.

\subsection{Analysis of the Learners Roles}

Learners, who are mostly native computer and internet users, that is they have been observing their family members using computers since early childhood, may find learning through technology in non-native languages with colleagues from other countries as part of their life. They need guidelines how to use digital tools for learning so they appreciate the fact that they use the technology in schools naturally. They would probably be more surprised if they did not, as computers are tools of their everyday life. It is estimated that by the age of 21 , a young person may spend 15 thousand hours in formal education, 20 thousand hours sitting in front of a TV and 50 thousand hours in front of a computer screen. That is why building habits of independent learning with the use of computers and via the internet becomes very important.

For many native computer users, the participation in eTwinning projects gives a chance to develop computer skills in a way that is useful for the school community. For many, it is an occasion to give up computer games and present their technical competences in authentic communication with partners. Moreover, they may appreciate the importance of intercultural skills and proficiency in foreign languages. For less privileged learners, who do not have access to computers at home, learning via technology in international groups at school and participation in a project may be the only chance to acquire simultaneously some technological, intercultural and linguistic skills for life. In this sense, the role of eTwinning in preventing digital divide should be strongly highlighted.

Teenagers are usually very interested in teen culture, they eagerly search for differences and similarities as they intensively build their personal, national and European identity. That is why, the group of projects about teen culture is presented separately in the gallery, however, they overlap with the ones about everyday culture.

In the projects learners collaborate among themselves within a group, with partners abroad, with their teacher and other teachers of different subjects. It happens, that the attitude of a passive receiver of teacher's orders, whose role is to answer quickly the teacher's questions, change into the attitude of a collaborator, who is able to decide on his or her tasks, their content, range and quality. Some students from educationally inefficient families, where there is no tradition of cooperation with teachers, may have problems with it. The satisfaction they get in communication with peers abroad may help them to overcome such attitude.

\subsection{Analysis of the Technology Used}

A variety of digital tools available in schools is used. Although the essence of a good project is the pedagogically sound use of any technology available at partners' school, the higher the technology the more fun and attractive the project is, which young people can appreciate. Below in Table 2, there is an alphabetical list of programs, applications and websites used by teachers to collaborate in projects submitted to European eTwinning contest. 
Table 2. List of software used in eTwinning projects.

\begin{tabular}{|c|c|c|}
\hline List of Programes & List of Programs Continued & List of Programs Continued \\
\hline Accuweather & JigsawPlanet & Proshow \\
\hline Adobe & Jing & PurposeGames \\
\hline Animoto & Kahoot & Quizlet \\
\hline AnswerGarden & Kizoa & ReadWriteThink \\
\hline Anyvideoconverter & KwikSurveys & screedbot \\
\hline Audacity & LCD Text generator & ScribbleMaps \\
\hline authorSTREAM & LearningApps & Scribd \\
\hline Blaberizzer & Lino & SketchToy \\
\hline blog & Littlebirdtales & Skype \\
\hline blogspot & Masher & Sliderocket \\
\hline Bomono & Max Console & Slideshare \\
\hline bookemon & Media ImpressionVoki & SlideTalk \\
\hline Calameo & MIND42 & Smart Notebook 11 \\
\hline ClassDojo & Mindmeister & Smilebox \\
\hline ClassTools & Mindomo & SmileBox \\
\hline Comic Life & Monkey Jam & Smore \\
\hline Comic Master & Moovly & SodaHead \\
\hline Crazy Talk & Movie Maker & Sony Vegas \\
\hline DomoAnimate & MS Excel & Spicynodes \\
\hline DomoNation & MS PowerPoint & Storybird \\
\hline Dvolver & MS Word & Storybord \\
\hline Educaplay & OneTrueMedia & Surveymonkey \\
\hline Elfyourself & ooVoo & Tagxedo \\
\hline e-mail & Padlet & Thinglink \\
\hline ESLvideo & Paint & ToonDoo \\
\hline Fipsnack & Pearltrees & Trip Advisor \\
\hline Flash Gear & Photo Peach & Tripline \\
\hline Flashmeeting & Photo Puzzle Maker & Typeform \\
\hline FlashVortex.com & Photobucket & Vacaroo \\
\hline FlickDraw & PhotoPeach & Vcasmo \\
\hline Flickr & Photoshop & Videojug \\
\hline FormatFactory & Photoshow & Vimeo \\
\hline Fotobabble & Photosnack & VocabularySpellingCity \\
\hline Fotor & Picasa Web Album & Vocaroo \\
\hline Freeonlinesurveys & Picture Manager & VoiceThread \\
\hline Gimp & Picture Trail & Voki \\
\hline Glitter Graphic & PinnaclePaint & Voxopop \\
\hline Glogster & Pixorial & WeTransfer \\
\hline GoAnimate & Pixrl & WhatsUp \\
\hline Google docs & Pixton & Wondershare \\
\hline Google earth & Pizap & Word Cloud \\
\hline Google maps & Polldaddy & Worditout \\
\hline Iclone v. 2 & PollSnack & Wordle \\
\hline Iclone v.4.1 & Popplet & WordPicasa 3 \\
\hline ImageChef & Postmywall & Wordsearchmaker \\
\hline imgur & PowToon & YouTube \\
\hline IrfanView & Powtoon & Zondle \\
\hline iSpring & Prezi & ZooBurst \\
\hline Isuu & ProProfs & \\
\hline
\end{tabular}

The extensive list above illustrates the impact of telecollaboration on both teacher technical professional development and student awareness of digital educational instruments.

\subsection{Analysis of the Results of the Projects}

There are two kinds of the results of work done in projects. The first kind is the end-product that represents visible effects and may be presented to others. In each project teachers and learners prepare 
digital materials such as presentations, photos, films, articles for project websites. They also produce brochures, books, posters, drawings. They record theatre performances, shows, meetings interviews, songs. Most of the materials are carefully prepared and the authors may be very proud of the results. The materials submitted for national or European contests are of very high quality. It is very important to produce a result that can be presented and shared. Other learners or teachers may make use of it. These results are very important in the short term. They document clearly and visibly the work done.

The second kind of the results represents the process of learning and cooperating. On the one hand, it is difficult to measure how much motivation to learn languages, to use technology increased. It is even more difficult to assess emotions such as friendship, satisfaction and pleasure experienced by participants. Many skills and competences acquired in the projects are used in everyday life. On the other hand, it is easy to forget how many real and imaginary barriers of various kinds disappeared, routines abandoned, not mention xenophobia and stereotypes that proved to be false. Some people do not even notice changes in their beliefs and attitudes towards openness to other cultures, social inclusion and tolerance. These results are not visible but in the long term they build ground for the future of participants both learners and teachers.

\subsection{Analysis of the Project Integration in the School Learning Environment and Life}

Different approaches to the international cooperation are presented in the projects. Some schools had started collaboration with partners from other countries before the eTwinning program was introduced. Thus, they registered the continuation of their previous activities as projects. This means that eTwinning responds to the demand for international links. Some projects are unique and single actions with a clear beginning and end, they usually last for a short time. They are recommended for teachers who start international collaboration. Short-term activity provides useful experience and confidence for the decision on the further steps. Other projects are perceived as a safe and good starting point for a planned long-term cooperation between the schools including exchange of students in the future within Erasmus+ programme. The scale of collaboration also varies in schools from one class involved in the project to the whole school and its policy with many classes involved in various projects. In these schools both teachers and learners learn-by-doing and the school becomes an international learning organization. It is observed how important social similarities and differences are in collaboration. Although schools from extremely different social contexts may succeed in a project, the more learners have in common, the better. Cooperation between two schools located in similar rural or industrial areas, or summer or winter holiday resorts seems to be easier and more satisfactory for the participants. Even though eTwinning aims at all forms of school collaboration, the social aspect is worth taking into consideration at the initial stage of searching for partners. All in all, international collaboration enriches the learning environment.

Within a school, teachers also use various modes of internal collaboration. In some projects one teacher is responsible for almost all work done. She or he contacts the partners, organizes both the external project with a partner school and the internal project in the Polish school. Then, the same teacher supervises learners' activities and checks the quality of the results of the project. In other schools the role of a coordinator is shared: one teacher is responsible for the organization of the project but the work is shared between teachers of different subjects. For example, the language teacher contacts the other school and supervises all linguistic activities and helps to translate materials. The ICT teacher supervises all work on the website, blog or digital photography or video. Science teachers take the part covered by their subjects. The Biology Geography and History teachers give advice or provide some idea on local nature, landscapes and culture. The Maths teacher helps to do calculations and statistics. The Art and Music teachers supervise artistic activities. Sometimes Headmaster takes on the responsibility of the coordinator but it is not a rule. In some projects, a coordinator is a person who contacts with the partner school. In another mode of work all teachers participating in the project maintains contacts with their counterparts in the partner school. It is obvious that the share of work and ways of collaboration depend on the teachers, content of the project and number of learners 
participated. It is important to emphasise that one teacher with a small group of learners and one computer may build up a project as sound and beneficial for students as a large group of teachers with hi-tech infrastructure.

\subsection{Analysis of the Global Issues in Education}

Many participants of projects coordinated by one country emphasize that the idea of twin immediately transforms into the idea of multi, as the human willingness to communicate is unlimited. Although the idea of the eTwinning programme promotes cooperation of two schools as embedded in the eTwinning name, willingness to cooperate overcomes the limits of two and there are many projects in which schools from various countries cooperate on the same topics. This is an additional value for teachers and learners. When schools gain more experience and confidence in international collaboration the number of teachers and students participating in it increases.

On the one hand, in the global culture of the world with people watching the same films and news on TV, reading the same books, eating the same food and having access to internet resources in all countries, educational institutions cannot remain closed in classrooms and school buildings as relics of the nineteenth century. The external pressure of civilization opens them up. Through the international collaboration the dreams of the first computing pioneers in education have come true. On the other hand, human nature desires diversity, longs for personal and social identity and a sense of belonging to a social group with its particular signs, features and behaviour. The two driving forces, that is, globalisation and desire of diversity, create a conflict that young generation should become aware of. As the number of multicultural contacts is growing, children have to learn from the early age how to respect 'others' and 'their values' as well as assert 'ourselves' and preserve 'our values' in the 'global village'.

\subsection{Analysis of the Role of the Projects in Local Community}

The role of eTwinning projects grows in local communities. Parents and even grandparents take part in the projects, particularly, if the topic relates to their youth. They willingly fill in questionnaires, they agree to be interviewed about old customs. They share their experience, talk about dramatic events of their lives, history of the town or region. Thanks to such activities a generation gap diminishes. Thus, eTwinning provides ground for better cohesion between generations, integrates generations.

Students often present results of the project work, e.g., dance shows, exhibitions of pictures or posters. They publish multilingual web sites about history and cultural events of their own town on region to attract tourists' attention. They prepare multilingual brochures to promote local tourist attractions. Students naturally join the community activities. They become citizens, who take care of the nature, historical remains and traditions.

Local authorities supported educational activities of the partners. eTwinning project results are presented during a twin towns festival. Representatives of local authorities participate in many school activities related to the school projects, they also come to celebrate eTwinning week. Sometimes links to multilingual descriptions of the history and tourist attractions of the town published on school websites are added to the community website. It is worth promoting the multilingual descriptions, e.g., in information boards on historical buildings or town authorities' boards. We may imagine how impressed could be a foreigner from a distant country who can read a notice about a small Polish town in his or her own language. Support provided by local authorities, mayors of towns and heads of villages, educational authorities, curators, inspectors acts as a catalyst for changes in education promoted in eTwinning action. 


\section{Discussion}

\subsection{Integration as the Ground for Each Project}

Integration of interdisciplinary knowledge and skills is embedded in the construction of each eTwinning project. Teachers and learners interact in at least one common language, native or non-native for the partners, through technology. Whatever topic of interaction they select, they develop collaboratively various skills: linguistic, communicational, technical, intercultural, thematic, organizational, managerial, etc.

\subsection{Integrating Multilingual Community of Practice}

Collaborating teachers and students build a community of practice which resembles, in a small scale, real life, which is multilingual, multicultural and equipped with various digital devices. Participation in the project provides opportunities for integrating curriculum as it gives learners opportunities to develop a broad range of competences: linguistic, intercultural, subject and technical. The language of communication in writing and speech takes place in various languages. However, English is the main language used by partners. Contact with Less Commonly Learnt and Taught Languages develops plurilingual competence. The topics are selected by both the teachers and by their learners according to their interests and individual aims. Thus, learning becomes more individualized and emotionally involving. Working in groups, both in-class and with partners abroad, creates many occasions for exchanging views and opinions, organizing and presenting them with a clear communicative aim. By using e-mail, chats, forums, creating and publishing web pages they develop reading and writing in genres characteristic for digital means of communication. Thus, they learn how to write hypertext, add graphics to electronic texts and use abbreviations in chats. They also prepare brochures and booklets for print in traditional genres, so the variety of text types is extended. Linguistic development in social contact is interrelated with intercultural awareness. Their motivation to learn selected languages-mainly English as a global language and the need for them increase, because vocabulary and grammar are acquired for immediate, not future use.

\subsection{Integrating Cultural and Intercultural Awareness}

Through participation in the broader community of practice schoolchildren not only learn about other cultures but also understand their native culture and its values better. They discover common universal human values in broader than local context. Searching for such values is a main feature of growing up during school years. Children learn how to identify cultural similarities and differences and accept both of them in a non-judgmental way. They also learn how to differentiate behaviour accepted in another culture, which may be odd in the native culture, from behaviour which is unacceptable in any culture. Knowledge of the eTwinning partner's culture and intercultural experiences gained in the project build openness and tolerance towards other cultures in general. A positive attitude to people speaking different languages and having their own customs raises curiosity and helps to reduce the concept of foreignness and strangeness. Young people become "global citizens". The benefits of early intercultural experience seem to build democratic responsibility in the citizens of the future society and accept cultural diversity naturally, which is particularly important for children from monolingual regions and countries. It is noteworthy that cultural human values expressed in non-native languages are gained and shared via the Internet, which is available everywhere.

\subsection{Integrating Technology}

One of the prerequisite is the use of digital technology, the projects are based on technology as the main means of communication. Its use varies from very simple web 1.0 tools such as email or chat, to web 2.0 collaborative tools such as Learning Management Systems or digital audio or video blogs, wikis, social networking tools, mobile technologies, etc. Technology at any level serves its purpose: it is used as a tool for integrating various themes in education and personal and social development of its users. Schoolchildren acquire technical skills through the use of tools relevant to their cognitive 
potential, for example, small children can participate in videoconferences, teenagers can use social networking sites or forums. On the one hand, learners may notice the power of technology as a means of communication and source of information. On the other hand, they learn how to take responsibility for their web-creations, for information they send directly in texts, which they prepare and indirectly in the style, in which they cooperate. The early experience in using the Internet for learning may result the future in participation in professional communities of practice for lifelong learning.

\subsection{Integrating Teachers}

Participation in a project invites teachers of all subjects to take part in collaborative international education. Developing intercultural competence in learners, which is obvious for teachers of languages because it is the main reason and content of their work, does not seem to be obvious for teachers of non-linguistic subjects. Working on such subjects-for example, Maths, Biology and Sciencein a non-native language prepares learners for further education and work in international teams. However, teachers of these subjects may perceive developing intercultural and linguistic competence within their field as problematic, because of a lack of such educational tradition, absence of relevant issues in the syllabus and deficiency in their own linguistic knowledge and skills. Teachers build community of practice by working together, sharing good practice, good examples of international links and a better understanding of problems that teachers face. They also have the sense of belonging to the community of European teachers sharing a similar approach to multilingual, multicultural, technology-based education.

\subsection{Integrating Headmasters}

Participation in projects encourages headmasters to open their schools and provide opportunities for European international cooperation between teachers and learners regardless of geographical and cultural constraints. What is more, technological resources available in schools are used more extensively and effectively as tools for teaching and learning.

\subsection{Integrating Fun and Serious Learning}

The projects provide opportunities for having fun while learning and for enjoying working on the final products of one's own choice, while collaborating with people who are "other, alike, the same"-as expressed in the title of one project.

\subsection{Limitations to Curricular Integration}

Few projects are focused on topics other than "customs and traditions" The buzz-words "regional customs and traditions" are so vague: there are always people who live in the region and do not know the customs or traditions attributed to this region. The real problem is that the concept of culture is very broad and it is not precisely defined, which makes it difficult to formulate general statements about culture. Whose culture do the children describe when they write about culture? How much culture is there in non-culture orientated activities? The large number of culture-centred projects shows that the majority of language teachers prefer to handle topics related to culture (whatever it means) and literature. Most of them are not prepared to undertake topics related to non-linguistic subjects and are not interested in taking them. It seems that significant changes in pre-service and in-service language teacher training should be recommended.

Even though we accept a vague definition of culture, it is obvious that there are several spheres of culture: from everyday culture to high culture. The majority of the projects deal with routine activities-daily, weekly, or yearly routines-most of which usually constitute the content of textbooks. This "surface layer" of the broad concept of culture is perceived as the main educational issue. Attempts to handle more serious but also more difficult aspects of culture, can be found only in few projects. Projects that focus on Maths, Science, Geography, Economics, Informatics and the Environment are still a minority. They provide ground for CLIL (Content and Language Integrated Learning). Non-linguistic 
subject teachers are less interested or prepared to incorporate linguistic and intercultural issues in their curricula. It can, thus, be recommended, that the curricula of all subjects should include such issues as terminology in foreign languages and international collaboration. Sport appears rarely in the projects as a topic, it was sometimes mentioned in life styles. The proportion of "surface culture" to other subject orientated projects should be changed.

Troublesome and sometimes shameful social issues, various addictions such as alcohol, drugs, bullying and crime at school as well as tolerance to minorities of different types are rarely undertaken even if such problems are shared by both partners' communities. However, there is a controversy if such topic should be a matter of discussion at all. These topics can be a chance to prevent such troubles, to sensitize to the threat and to protect victims.

\subsection{Recommendations for the eTwinning Projects Development}

The following areas may be considered for further development:

- Age-more technology-enhanced work in secondary and vocational education;

- Range-more teachers and learners from each school engaged in telecollaboration;

- Regions-more participants from rural and less privileged areas;

- Learners' mode of work more collaboration, less cooperation-working together on one product rather than working separately on products for the partner;

- Teachers' collaboration-teachers of languages and non-linguistic subjects, who participate in one project in a school cooperate to develop teaching skills needed for CLIL (Content and Language Integrated Learning);

- Universal final results_other learners and teachers may make use of them; the results may be useful for the local community.

\subsection{Recommendations to Researchers in the Field of Education}

The project participants are members of community of practice. They are more engaged in building the international learning and teaching environment than researching it in a rigorous scientific study. The research initiative on the impact of eTwinning was based on questionnaires.

Thus, there is plenty of research areas for further studies with the use of quantitative, qualitative studies within a broad perspective of ethnographic approach. Content based studies with a reference to materials prepared or communication patterns used by the project partners are also interesting. The present study is an example of content analysis from the perspective of curricular integration.

To give some examples of potential perspectives of research:

- The innovative use of technology at various educational levels;

- The impact on teacher professional development-various aspects;

- The development of intercultural competence in learners and teachers;

- The patterns of communication used in successful projects;

- The reasons of drop-out and lack of satisfaction with collaborative work;

- The patterns of collaboration;

- The impact of the projects on linguistic development of the stakeholders;

- The dissemination of the project work;

- The role of educational models and traditions in various educational systems.

These areas may be examined at local level or in the form of comparative studies.

However, I would not recommend experimental studies, as it is controversial ethically to exclude one group of learners from the project in order to compare the results. It seems that the results could not be comparable as the local learning environment is hardly comparable with an international one with collaborative work with partners from other countries. I would also perceive effectiveness studies 
as controversial as good education is often oriented on long-term-goals. Thus, short term effects might be not noticed. The long-term effect even might not be predicted wisely.

\section{Conclusions}

To sum up, participation in eTwinning projects becomes an important factor that integrates curriculum, enhances CLIL, builds a broader community of practice through telecollaboration. IT enriches the learning environment and experience.

The eTwinning programme which has received such a wide response among educators fulfils the expectations of teachers, who use technology and languages as tools to prepare the young generation for the future. What is more, European educators have created a community of practice. Multifaceted analysis of the processes and results of the programme indicates the integrative tendencies, which take place in education. Focus on social interactions brings curriculum integration processes well adopted by the participants of the projects.

In the projects language and technology are enslaved for learning, communication, social, personal and professional development, for integration at different levels and with the use of different patterns. A community of practice prepares young people to life in a multilingual, multicultural world, in which people are networked according to their interests and preferences. For technology, it is the best way to disappear from the user's perception, in the sense, that it is used naturally without either any attention or emotion from the user [29].

Building on what has been already achieved in the eTwinning community of practice may involve more learners into such collaboration which is especially valid for regions where learners cannot experience intercultural co-existence on everyday basis.

Conflicts of Interest: The author declares no conflict of interest.

\section{References}

1. Pring, R. Curriculum integration. In The Philosophy of Education; Peters, R.S., Ed.; Oxford University Press: London, UK, 1973; pp. 123-149.

2. Jacobs, H.H. Interdisciplinary Curriculum: Design and Implementation; Association for Supervision and Curriculum Development: Alexandria, VA, USA, 1989.

3. Austin, J.D.; Hirstein, J.; Walen, S. Integrated mathematics interfaced with science. Sch. Sci. Math. 1997, 1, 45-49. [CrossRef]

4. Kain, D.L. Cabbages and kings: Research directions in integrated/interdisciplinary curriculum. J. Educ. Thought 1993, 3, 312-331.

5. Barab, S.A.; Landa, A. Designing effective interdisciplinary anchors. Educ. Leadersh. 1997, 6, 52-58.

6. Stanley, G. Language Learning with Technology: Ideas for Integrating Technology in the Classroom; Cambridge University Press: Cambridge, UK, 2013.

7. Lave, J.; Wenger, E. Situated Learning: Legitimate Peripheral Participation; Cambridge University Press: Cambridge, UK, 1991.

8. Dillenbourg, P. What do you mean by collaborative learning? In Collaborative Learning: Cognitive and Computational Approaches; Dillenbbourg, P., Ed.; Pergamon Elsevier Science: Amsterdam, The Netherlands, 1999; pp. 1-16.

9. Mishra, P.; Koehler, M.J. Technological Pedagogical Content Knowledge: A new framework for teacher knowledge. Teach. Coll. Rec. 2006, 6, 1017-1054. [CrossRef]

10. Knezek, G.; Christensen, R. The importance of information technology attitudes and competencies in primary and secondary education. In International Handbook of Information Technology in Primary and Secondary Education; Voogt, J., Knezek, G., Eds.; Springer: New York, NY, USA, 2008; pp. 321-331.

11. Higgins, J. Language, Learners and Computers: Human Intelligence and Artificial Unintelligence; Longman: London, UK, 1998. 
12. Meskill, C.; Ranglova, K. Sociocollaborative language learning in Bulgaria. In Network-Based Teaching: Concepts and Practice; Warschauer, M., Kern, R., Eds.; Cambridge University Press: Cambridge, UK, 2000; pp. 20-40.

13. Snyder, T.; Palmer, J. In Search of the Most Amazing Thing: Children, Education and Computers; Addison-Wesley: Reading, MA, USA, 1986.

14. Penfield, J. The Media: Catalysts for Communicative Language Learning; Addison-Wesley: Reading, MA, USA, 1987.

15. Papert, S. The Children's Machine: Rethinking School in the Age of the Computer; Basic Books: New York, NY, USA, 1993.

16. Wertsch, J.V. Vygotsky and the Social Formation of the Mind; Harvard University Press: Cambridge, MA, USA, 1985.

17. Crook, C. Computers and the Collaborative Experience of Learning; Roultedge: London, UK, 1994.

18. Chapelle, A.A. Is networked-based learning CALL? In Network-Based Teaching: Concepts and Practice; Warschauer, M., Kern, R., Eds.; Cambridge University Press: Cambridge, UK, 2000; pp. 204-228.

19. Byram, M. Teaching and Assessing Intercultural Communicative Competence; Multilingual Matters: Clevendon, UK, 1997.

20. O'Dowd, R.; Ritter, M. Understanding and working with "failed communication" in telecollaborative exchanges. CALICO J. 2006, 23, 623-642. [CrossRef]

21. Eurobarometer 224. Europeans, Science and Technology Special Issue. 2005. Available online: http://ec. europa.eu/public_opinion/archives/ebs/ebs_224_report_en.pdf (accessed on 19 November 2017).

22. Eurobarometer 340. Science and Technology Special Issue. 2010. Available online: http:/ / ec.europa.eu/public_ opinion/archives/ebs/ebs_340_en.pdf (accessed on 19 November 2017).

23. Dziennik Ustaw Rzeczypospolitej Polskiej. Rozporzadzenie Ministra Edukacji Narodowej z Dnia 14 Lutego 2017 r. Dziennik Ustaw Rzeczypospolitej Polskiej z Dnia 24 Lutego 2017, poz. 356 [Regulation of the Minister of National Education of 14 February 2017. Official Gazette of the Republic of Poland of 24 February 2017, item 356]; Dziennik Ustaw Rzeczypospolitej Polskiej: Warszawa, Poland, 2017.

24. Education for Change. Final Report-Study of the Impact of eTwinning on Participating Pupils, Teachers and Schools; Publications Office of the European Union: Luxembourg, 2013; ISBN 978-92-79-27789-4.

25. Crişan, G. The impact of teachers' participation in eTwinning on their teaching and training. Acta Didact. Napoc. 2013, 6, 19-28.

26. Nawrot, B. The impact of eTwinning projects on teachers' professional development in the context of the English and Polish educational system. EduAkcja 2018, in press.

27. Gajek, E. Implications from the Use of ICT by Language Teachers-Participants of International Projects. Univers. J. Educ. Res. 2015, 3, 1-7. [CrossRef]

28. eTwinning. Available online: https:/ / www.etwinning.net/en/pub/index.htm (accessed on 19 November 2017).

29. Bax, S. CALL-Past, present and future. System 2003, 31, 13-28. [CrossRef] 